\title{
Domestic Coercive Control and Common Mental Disorders among Women in Informal Settlements in Mumbai, India: a Cross-sectional Survey
}

\author{
Authors \\ Suman Kanougiya ${ }^{1}$, Nayreen Daruwalla ${ }^{2}$, Lu Gram $^{3}$, Muthusamy Sivakami ${ }^{1}$ and David Osrin ${ }^{3}$ \\ ${ }^{1}$ Tata Institute of Social Sciences (TISS), Mumbai, Maharashtra, India \\ ${ }^{2}$ SNEHA (Society for Nutrition, Education and Health Action), Mumbai, Maharashtra, India \\ ${ }^{3}$ Institute for Global Health, University College London, UK
}

\begin{abstract}
Coercive control behaviors central to the abuse of power appear more frequent than other types of domestic violence, but little is known about its frequency, features, and consequences for women in India. We aimed to examine the prevalence of domestic coercive control and its association with physical, sexual, and emotional domestic violence in the preceding year and symptoms of depression, anxiety, and suicidal thinking. In a crosssectional survey, we interviewed 4,906 ever-married women aged 18-49 years living in urban informal settlements in Mumbai, India. We developed a 24-item scale of coercive control, assessed physical, sexual, and emotional violence using existing questions, and screened for symptoms of depression with the Patient Health Questionnaire (PHQ9), anxiety with the Generalized Anxiety Disorder (GAD7) questionnaire, and suicidal thinking with questions developed by the World Health Organization. Estimates involved univariable and multivariable logistic regression models and the prediction of marginal effects. The prevalence of domestic coercive control was $71 \%$. In total, $23 \%$ of women reported domestic violence in the past 12 months (emotional 19\%, physical 13\%, sexual 4\%). Adjusted models suggested that women exposed to controlling behavior had greater odds of surviving emotional (aOR 2.1; 95\% CI 1.7, 2.7), physical (1.4; 1.0, 1.9), and sexual (1.8; 1.1, 3.0) domestic violence in the past 12 months; and higher odds of a positive screen for moderate or severe depression $(1.7 ; 1.3,2.2)$, anxiety $(2.1 ; 1.3,3.1)$, and suicidal thinking $(1.7 ; 1.2,2.3)$, and increased with each additional indicator of coercive control behavior. When women reported 24 indicators of coercive control, the adjusted predicted proportion with moderate or severe depressive symptoms was $60 \%$, anxiety $42 \%$, and suicidal thinking $17 \%$. Inclusion of coercive control in programs to support domestic violence, would broaden our understanding of domestic abuse to resemble most victims experience and improve interventions.
\end{abstract}

\section{Keywords}

Coercive control; domestic violence; common mental disorder; India 


\section{Background}

Preventing domestic violence against women is a global imperative (UN Assembly, 2000). Beginning to address it involves understanding that it is a constellation of behaviours, central to which is the abuse of power within the home. Most research has focused on physical and sexual violence and emotional and economic violence to a lesser degree (Howard et al., 2013; Kalokhe et al., 2016). However, bound up with these forms of violence is controlling behaviour in which family members use threats and violence to assert power over the survivor, who suffers negative consequences for non-compliance.

Coercive control involves abusers using a range of means to "hurt, humiliate, intimidate, exploit, isolate, and dominate their victims"(Stark, 2007). These include restricting or controlling movement and access to family, friends, neighbours, and broader social circles. Perpetrators often use gender norms to constrain women's mobility, time, spending, socialising, and diet. Women may, for example, be compelled to do household chores in a particular way or keep records of expenditure, the processes becoming normalised within gendered expectations to a point at which it is difficult to differentiate the coercive from the normative (Bishop \& Bettinson, 2017). The environment reflects, entrenches, and exaggerates social and gender norms and women's subordinate position in society (Williamson, 2010), potentially to the extent that it is not perceived as abusive. Coercive control tactics are often interpreted as expressions of care, affection, and love, rather than jealousy or proprietariness (Beck \& Raghavan, 2010; Dutton et al., 2006; Stark \& Hester, 2019; Suarez, 1994; Wolford-Clevenger et al., 2017).

Although survivors may not consider coercive controlling behaviour to be abuse (Richardson et al., 2020), it is more frequent than other types of domestic violence (Kelly \& Johnson, 2008). Across countries, between $21 \%$ and $90 \%$ of women have experienced controlling behaviour from a partner (Antai, 2011; García-Moreno et al., 2005; Graham-Kevan \& Archer, 2003; Johnson, 2006; Krantz \& Vung, 2009; Mandal \& Hindin, 2013; Sapkota et al., 2016). Such behaviour is not limited to specific conflicts or situations. It often manifests early in a relationship and escalates over time (Crossman et al., 2015; Hardesty et al., 2015). Most—but not all—cases include other forms of abuse such as physical or sexual violence (Anderson, 2008; Lischick, 1999). Studies suggest that coercive control can precede, motivate, or increase the likelihood of other types of violence in relationships (Aizpurua et al., 2021; Antai, 2011; Dalal \& Lindqvist, 2010; Graham-Kevan \& Archer, 2003; Hardesty et al., 2015; Howard et al., 2013; O'Leary et al., 1994; Stark, 2012), particularly when controlling behaviour does not achieve the desired effect (Tanha et al., 2009). There is evidence from studies in India and elsewhere that partners who use coercive control are between three and eight times more likely to perpetrate physical or sexual violence than partners who use physical violence alone (Kelly \& Johnson, 2008; Mukherjee \& Joshi, 2019; Ram et al., 2019), and that cases involving coercive control are more likely to result in serious harm than cases that involve discrete acts of physical violence (Campbell et al., 2003; Dobash \& Dobash, 2015; Myhill \& Hohl, 2016; Stark, 2007).

Coercive control appears to be common in India, affecting approximately $50 \%$ of women of reproductive age (International Institute for Population Sciences \& ICF, 2017; Mukherjee \& Joshi, 2019; Richardson et al., 2020). The prevalence estimated from the fourth National Family Health Survey (NFHS-4) was higher in rural than in urban areas and among women with less education and poorer socioeconomic position. Women who reported more instances of controlling behaviour reported higher rates of emotional (54\% compared with 5\%), physical 
(64\% compared with $17 \%$ ), and sexual violence (30\% compared with $2 \%$ ) than women who did not(International Institute for Population Sciences (IIPS) \& ICF, 2017).

Coercive control harms mental health (Follingstad et al., 1990; Tolman, 1992). A range of symptoms has been described(Dutton et al., 1997; Follingstad et al., 1991), including distress (Richardson et al., 2020) and common mental disorders such as anxiety and depression (Abbott et al., 1995; Bergman \& Brismar, 1991; Dutton et al., 1999; Leone, 2010; Richardson et al., 2020; Williamson, 2010; Wolford-Clevenger et al., 2017). Although some studies have examined coercive control in India (Dalal \& Lindqvist, 2010; Kalokhe et al., 2018; Mukherjee \& Joshi, 2019; Pandey et al., 2009; Ram et al., 2019), knowledge of the implications for mental health is limited (Richardson et al., 2020; Varma et al., 2007).We wanted to understand women's experiences in urban informal settlements and the risk of harm to their mental health. Our objectives were to examine (1) the prevalence of coercive control, (2) its associations with other forms of domestic violence, and (3) its relationship with depression, anxiety, and suicidal thinking.We hypothesized that coercive control would be common, that it would be associated with other forms of abuse, and that it would be a risk factor for depression, anxiety, and suicidal thinking.

\section{Methods}

\section{Setting}

The study was conducted in urban informal settlements in Mumbai. Informal settlements (slums) are characterised by overcrowding and unsanitary, unhealthy, and dehumanising living conditions. They are subject to insecure land tenure, lack of access to safe drinking water, sanitation, drainage, solid waste management, internal and approach roads, street lighting, education and health care, and low-quality shelter (Chandramouli, 2011; United Nations Human Settlements Programme (UN-Habitat), 2003). A significant proportion of slum dwellers face social burdens and health problems worse than their non-slum and rural counterparts.

\section{Design}

We used data from a survey done before a community-based intervention to prevent violence against women implemented by the non-government organisation SNEHA (Society for Nutrition, Education and Health Action), which has run a program focusing on primary, secondary, and tertiary prevention of violence for 20 years in informal settlements in Mumbai (Daruwalla et al., 2019). The cross-sectional systematic random sample survey included 50 clusters of equal size ( $\sim 100$ respondents from $\sim 500$ residential households) in two sizeable informal settlement areas.

\section{Participants}

We interviewed 5122 women aged 18-49 years in a survey designed to understand domestic violence perpetrated by intimate partners and other family members. For this analysis, we limited the dataset to 4906 ever-married women.

\section{Data Collection}

We followed WHO guidelines for research on domestic violence against women (WHO, 2012) and on sexual violence (Jewkes et al., 2012). Details of data collection are available elsewhere (Daruwalla et al., 2020). Briefly, 16 women interviewers with graduate education and three months of training mapped the study areas and visited households to enumerate residents and list 
potential respondents. From a random starting point in each cluster, alternate households were selected without replacement until we had collected information from 100 women aged 18-49 years (Daruwalla et al., 2020). Because younger women with a disability may be at higher risk of domestic violence (Ellsberg \& Heise, 2005), when more than one potential respondent was available in a household, an algorithm led the investigators to select the youngest disabled, youngest married, or youngest unmarried woman. Interviews were arranged in advance to maintain privacy, with a provision for up to three repeat visits. Participants were given a participant information sheet, discussed the nature of the interview and right to withdraw, and gave signed consent. The interview protocols included safety assessment, counselling, liaison with healthcare, police, and legal services, and developing follow-up plans for the survivor and her family (all of these with permission from the survivor). Interviewers used electronic tablets to enter information in a database in CommCare (www.dimagi.com).

\section{Variables}

\section{Sociodemographic variables}

Marital status was described by a categorical variable distinguishing married respondents from respondents who had been widowed, separated, or divorced. Socioeconomic position was described by quintiles of a standardised score derived from the first component of a principal components analysis of the ownership of 22 assets (Filmer \& Pritchett, 2001; Vyas \& Kumaranayake, 2006).

\section{Exposure: Coercive Controlling Behaviour}

Measures of coercive control have not yet been validated in India or elsewhere (Beck \& Raghavan, 2010; Dutton et al., 2006; Kirkwood \& Gilbert, 1995; Tanha et al., 2009), and questionnaires about psychological abuse do not clearly differentiate coercive control from psychological abuse (Dekeseredy \& Schwartz, 2011; Dutton et al., 2006; Myhill, 2015; Straus et al., 1996). Therefore, we developed a 24-item domestic coercive control questionnaire based on programme experience supporting violence survivors, augmented by four focus group discussions with counsellors, community actors, and lawyers. We harmonized items as far as possible with existing questions available in Demographic and Health Surveys and other studies. The categories of response to each question were no, sometimes, or all the time. Taking a conservative approach, we coded response as indicating the experience of an item of coercive control if a woman said that she had suffered it all the time. In terms of numbers of different tactics rather than frequency, we described domestic coercive control intensity in a summative variable with values from 0 to 24 .

\section{Outcomes}

Participants were screened for symptoms suggestive of depression with the Patient Health Questionnaire 9 (PHQ-9) (Kroenke et al., 2001), and symptoms suggestive of anxiety with the Generalised Anxiety Disorder 7 (GAD-7) (Löwe et al., 2008 ; Spitzer et al., 2006), each referring to the last two weeks. Items were coded 0 (not at all), 1 (several days), 2 (more than half the days), or 3 (nearly every day). PHQ-9 scores of 10-27 were taken as suggesting moderate or severe depression(Löwe et al., 2004), and GAD-7 scores of 10-21 moderate or severe anxiety. We used binary variables to describe these outcomes in the analysis. Suicidal thinking was assessed with the question, "In the past 12 months, did you ever consider attempting suicide?"(McKinnon et al., 2016). 
The selection of questions to describe emotional, physical, and sexual abuse by an intimate partner or other family member is described elsewhere (Daruwalla et al., 2020). Five questions described emotional violence (insulted or made to feel bad about herself; ignored or treated indifferently; belittled or humiliated in front of others; scared or intimidated on purpose; threats to hurt her or someone close or take her child away), physical violence by nine (pushed, shoved, shaken, hurt; twisted arm, banged head, pulled hair; slapped, pinched, bitten; hit, punched; kicked, dragged, beaten; things thrown at, burned; attacked or threatened with sharp objects or blunt objects; suffocated, choked, hung, poisoned), and sexual violence by four (forced intercourse; forced other degrading act; threatened other act; forced to replicate pornography). Women's affirmative response to any of these questions - lifetime or past year - was described by binary composite variables for physical violence, sexual violence, and emotional violence.

Cronbach's alpha indicated internal consistency for the PHQ-9 ( $\alpha$ 0.86), GAD-7 ( $\alpha$ 0.84), nine items on physical abuse ( $\alpha 0.83)$, four items on sexual abuse ( $\alpha 0.76)$, five items on emotional abuse ( $\alpha 0.82)$, and 24 items on coercive control $(\alpha 0.80)$.

\section{Statistical Analysis}

We tabulated frequencies and proportions of demographic and socioeconomic variables and responses to questions about coercive control, the experience of physical, sexual, and emotional violence, depression, anxiety, and suicidal thinking. Associations between coercive control and other forms of violence were examined by cross-tabulation, followed by univariable and multivariable logistic regression models. We examined the association of coercive control (determinant) with moderate or severe depression, moderate or severe anxiety, and suicidal thinking in the last 12 months (outcomes) in a series of univariable and multivariable logistic regression models. We computed unadjusted and two adjusted models: the first multivariable logistic regression model (aOR1) was adjusted for respondent age, education, religion, caste, asset quintile, respondent and husband employment, respondent and husband drug or alcohol use. The second model (aOR2) was adjusted for other forms of domestic violence and the first model variables (aOR1).

We did two additional analyses. First, we examined the effect of increasing numbers of positive responses to coercive control questions on moderate or severe depression, moderate or severe anxiety, and suicidal thinking in the last 12 months. We adjusted the logistic regression models in the same way as above and then predicted marginal effects and modelled the log-odds of common mental disorder as a step function from 0 to 1 act of control, followed by a linear increase from 1 to 24 acts. We tested for non-linearity by fitting a quadratic term for the increase from 1 to 24 .

Second, we analysed possible coercive control sources: either intimate partner or other marital family members. Of the 24 items in our questionnaire, 16 that made this distinction were available. We replicated the analyses described above using this smaller number of coercive control indicators, recategorising the exposure and allowing for effect modification by an intimate partner, a marital family member, or both. All estimates accounted for survey design, with the cluster as the primary sampling unit, four larger areas as strata, and standard errors estimated by Taylor linearisation using svy commands in STATA 15.0 (StataCorp LLC). 


\section{Ethical Considerations}

Ethical approval was granted by the UCL Research Ethics Committee (3546/003, 27/09/2017) and by PUKAR (Partners for Urban Knowledge, Action, and Research) Institutional Ethics Committee (25/12/2017). The trial before which the data were collected is registered with the Controlled Trials Registry of India (CTRI/2018/02/012047) and ISRCTN (ISRCTN84502355).

\section{Results}

Table 1 summarises the characteristics of 4906 ever-married women aged 18-49 years. Around $19 \%$ had no schooling and $38 \%$ had reached middle school. A quarter of women were in remunerated work — although 20\% of them earned less than INR 12,000 a year (USD 163) — and $98 \%$ of their partners were in remunerated work with a mean annual income of INR 172,383 (USD 2335). More than half identified as of general caste. 12\% said that they used alcohol or drugs, compared with $44 \%$ of their husbands.

Table 1. Characteristics of 4906 Ever-married Women Respondents in Informal Settlements in Mumbai, India

\begin{tabular}{|c|c|c|}
\hline Marital status & $(\mathrm{n})$ & $(\%)$ \\
\hline Currently married & 4694 & (96) \\
\hline Widowed/Separated/Divorced & 212 & $(4)$ \\
\hline \multicolumn{3}{|l|}{ Respondent age (in complete years) } \\
\hline $18-25$ y & 1025 & $(21)$ \\
\hline $26-30$ y & 1421 & (29) \\
\hline $31-36$ y & 1172 & (24) \\
\hline $37-49$ y & 1288 & (26) \\
\hline \multicolumn{3}{|l|}{ Respondent education } \\
\hline No education & 938 & (19) \\
\hline Primary $1-5$ y & 846 & (17) \\
\hline Middle 6-8 y & 1099 & (22) \\
\hline High 9-10 y & 1105 & (23) \\
\hline Senior $11-12$ y & 533 & (11) \\
\hline Above 12 y & 385 & (8) \\
\hline Respondent employed & 1182 & (24) \\
\hline \multicolumn{3}{|l|}{ Respondent monthly income, INR } \\
\hline$<1000$ & 233 & $(20)$ \\
\hline 1000-2999 & 303 & (27) \\
\hline $3000-5999$ & 279 & (25) \\
\hline $6000+$ & 322 & $(28)$ \\
\hline Respondent uses alcohol or drugs & 612 & (12) \\
\hline \multicolumn{3}{|l|}{ Husband age } \\
\hline $18-19$ y & 14 & $(<1)$ \\
\hline $20-29 y$ & 917 & (19) \\
\hline $30-39 y$ & 2102 & (44) \\
\hline $40-49$ y & 1370 & (29) \\
\hline $50+y$ & 391 & (8) \\
\hline Husband employed & 4686 & (98) \\
\hline \multicolumn{3}{|l|}{ Husband monthly income, INR } \\
\hline$<10,000$ & 1095 & (23) \\
\hline $10,000-11,999$ & 997 & (21) \\
\hline $12,000-14,999$ & 652 & (14) \\
\hline $15,000+$ & 1942 & (41) \\
\hline Husband uses alcohol or drugs & 2100 & $(44)$ \\
\hline \multicolumn{3}{|l|}{ Housing type } \\
\hline Kachha (insubstantial) & 336 & (7) \\
\hline
\end{tabular}




\begin{tabular}{|lrr|} 
Pukka (robust) & 2518 & $(51)$ \\
Mixed & 2052 & $(42)$ \\
Toilet type & & \\
Private & 836 & $(17)$ \\
Public & 4368 & $(82)$ \\
Open defecation & 2 & $(<1)$ \\
Religion & 1826 & $(37)$ \\
Hindu & 2882 & $(59)$ \\
Muslim & 198 & $(4)$ \\
Other & & \\
Caste & 2854 & $(58)$ \\
General & 1180 & $(24)$ \\
OtherBackward Caste & 872 & $(18)$ \\
Scheduled Tribe or Caste & & \\
Socioeconomic quintile & 969 & $(21)$ \\
1 poorest & 936 & $(20)$ \\
2 & 934 & $(20)$ \\
3 & 933 & $(20)$ \\
4 & 935 & $(20)$ \\
5 least poor & 4906 & $(100)$ \\
\hline All & &
\end{tabular}

Table 2 summarises the prevalence of coercive controlling behaviour, domestic violence, and selected common mental disorders. Overall, $71 \%$ of women reported experiencing at least one of the 24 items. The most commonwas that their socialisation, mobility, and access to resources were restricted. Widowed, divorced, or separated women had greater odds of experiencing coercive control than currently married women (adjusted odds ratio 3.2; 95\% CI 1.6, 6.8). Forms of violence other than coercive control were also common: $23 \%$ reported domestic violence in the last year, of which emotional violence was the most common. Overall, $9 \%$ of women screened positive for moderate or severe depressive symptoms on the PHQ-9, 6\% for anxiety on the GAD-7, and 6\% reported suicidal thinking in the last year.

Table 2. Prevalence of Coercive Controlling Behaviour, Domestic Violence, and Common Mental Disorders among 4906 Ever-married Women Respondents in Informal Settlements in Mumbai, India

\begin{tabular}{|lrr|}
\hline Coercive control behaviour & $\mathbf{( n )}$ & $\mathbf{( \% )}$ \\
Dress or hairstyle dictated by others & $\mathbf{3 4 6 5}$ & $\mathbf{( 7 1 )}$ \\
Excluded from family matters & 256 & $(5)$ \\
Needs permission for healthcare & 357 & $(7)$ \\
Limited access to household areas & 711 & $(14)$ \\
Forced out of house & 168 & $(3)$ \\
Locked in house & 162 & $(3)$ \\
Prevented from attending meetings & 37 & $(1)$ \\
Movement monitored & 220 & $(4)$ \\
Prevented from seeking employment & 386 & $(8)$ \\
Coerced to seek employment & 825 & $(17)$ \\
Prevented from schooling & 76 & $(2)$ \\
Given excessive work & 148 & $(3)$ \\
Coerced to use contraception & 236 & $(5)$ \\
Prevented from using contraception & 15 & $(<1)$ \\
Prevented from terminating pregnancy & 52 & $(1)$ \\
Coerced to terminate pregnancy & 37 & $(1)$ \\
Never free to talk on phone & 14 & $(<1)$ \\
\end{tabular}


\begin{tabular}{lrr|} 
Never free to speak & 501 & $(10)$ \\
Needs permission to go out & 1245 & $(25)$ \\
Accompanied when out & 510 & $(10)$ \\
Never allowed out in evening & 652 & $(13)$ \\
Can never meet female friends & 488 & $(10)$ \\
Can never meet male friends/acquaintances & 2388 & $(49)$ \\
Can never meet natal family & 249 & $(5)$ \\
Domestic violence in last $\mathbf{1 2}$ months & 1104 & $(23)$ \\
Physical violence & 618 & $(13)$ \\
Sexual violence & 186 & $(4)$ \\
Emotional violence & 927 & $(19)$ \\
Domestic violence (lifetime) & 1877 & $(38)$ \\
Physical violence & 1243 & $(25)$ \\
Sexual violence & 285 & $(6)$ \\
Emotional violence & 1553 & $(32)$ \\
Common mental disorder & & $(9)$ \\
Moderate or severe depression on PHQ-9 & 443 & $(6)$ \\
Moderate or severe anxiety on GAD-7 & 299 & $(6)$ \\
Suicidal thinking in last 12 months & 318 & $(100)$ \\
\hline All
\end{tabular}

PHQ-9: Patient Health Questionnaire 9-question screen. GAD-7: Generalised Anxiety Disorder 7question screen.

Crude and both adjusted logistic regression models suggested that women who reported coercive control had greater odds of experiencing emotional (adjusted odds ratio: 2.1 ; 95\% CI 1.7, 2.7), physical $(1.4 ; 1.0,1.9)$, and sexual $(1.8 ; 1.1,3.0)$ violence in the last 12 months. Table 3 shows associations of coercive control and emotional, physical, and sexual domestic violence with positive screens for depression, anxiety, and reported suicidal thinking. Adjusted models suggested that reported coercive control was associated with greater odds of a positive screen for moderate or severe depression (aOR2 $1.7 ; 1.3,2.2)$, independently of the three other forms of domestic violence. Similar findings were seen associating reported coercive control with a positive screen for moderate or severe anxiety (aOR2 2.1; 1.3, 3.1) and suicidal thinking (aOR2 $1.7 ; 1.2,2.3)$. Emotional violence independently increased the odds of a positive screen for depression, anxiety, or suicidal thinking three-to-four-fold.

Table 3. Association of Coercive Control Behaviour with Depression, Anxiety, and Suicidal thinking among 4906 Ever-married Women Respondents in Informal Settlements in Mumbai, India

\begin{tabular}{|c|c|c|c|c|c|c|c|}
\hline & No & $(\%)$ & Yes & $(\%)$ & OR [95\% Cl] & $\mathrm{OR}_{1}[95 \% \mathrm{Cl}]$ & $\begin{array}{l}\mathrm{OR}_{2}[95 \% \\
\mathrm{Cl}]\end{array}$ \\
\hline \multicolumn{8}{|c|}{$\begin{array}{l}\text { Outcome: Moderate or severe depression on PHQ-9 screen } \\
\text { Exposures } \\
\text { Coercive control behaviour }\end{array}$} \\
\hline No & 1368 & (95) & 73 & (5) & 1 & 1 & 1 \\
\hline Yes & 3095 & (89) & 370 & (11) & $2.2[1.8,2.8]$ & $2.2[1.8,2.9]$ & $1.7[1.3,2.2]$ \\
\hline \multicolumn{8}{|l|}{ Emotional violence in Last $12 \mathrm{~m}$} \\
\hline No & 3759 & (94) & 220 & (6) & 1 & 1 & 1 \\
\hline Yes & 704 & (76) & 223 & (24) & $5.4[4.4,6.7]$ & $4.8[3.9,6.0]$ & $3.3[2.5,4.3]$ \\
\hline \multicolumn{6}{|l|}{ Physical violence in last $12 \mathrm{~m}$} & & 1 \\
\hline Yes & 467 & (76) & 151 & (24) & $4.4[3.5,5.6]$ & $4.0[3.1,5.2]$ & $1.5[1.1,2.1]$ \\
\hline \multicolumn{8}{|l|}{ Sexual violence in last $12 \mathrm{~m}$} \\
\hline $\begin{array}{r}\text { No } \\
\text { Yes }\end{array}$ & $\begin{array}{c}4336 \\
127\end{array}$ & $\begin{array}{l}(92) \\
(68)\end{array}$ & $\begin{array}{c}384 \\
59\end{array}$ & $\begin{array}{l}(8) \\
(32)\end{array}$ & $\begin{array}{l}1 \\
5.3[3.8,7.3]\end{array}$ & $\begin{array}{l}1 \\
4.5[3.1,6.5]\end{array}$ & $\begin{array}{l}1 \\
1.8[1.3,2.7]\end{array}$ \\
\hline
\end{tabular}




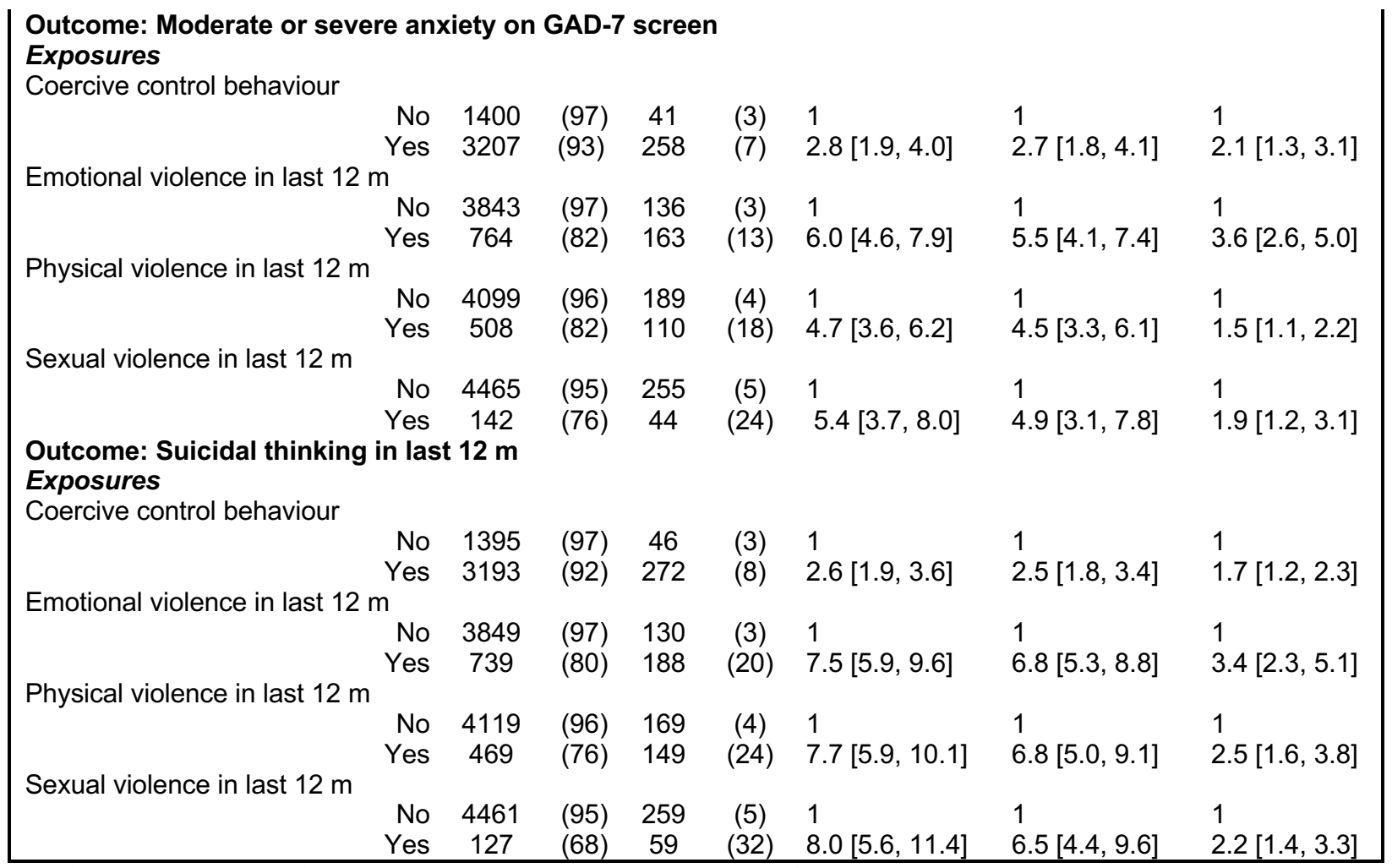

PHQ-9: Patient Health Questionnaire 9-question screen. GAD-7: Generalised Anxiety Disorder 7-question screen. OR: crude odds ratio. $\mathrm{aOR}_{1}$ : odds ratio adjusted with covariates for respondent age, education, religion, caste, socioeconomic quintile, respondent and husband employment, respondent and husband drug or alcohol use. $\mathrm{aOR}_{2}$ : odds ratio adjusted as $\mathrm{aOR}_{1}$ plus covariates for emotional, physical, and sexual violence.

Figure 1 shows the effects of coercive control on depression, anxiety, and suicidal thinking based on conditional logistic regression models. For each outcome, predicted marginal effects are presented for three models: crude, adjusted with sociodemographic covariates, and adjusted with both sociodemographic covariates and covariates describing the other three forms of violence. The fully adjusted model showed that, in the absence of coercive behaviour, the predicted proportion of women with depression was $6 \%$, with anxiety $3 \%$, and with suicidal thinking $4 \%$. These proportions increased for each additional indicator of coercive control that women reported. When women reported 24 indicators of coercive controlling behaviour, the predicted proportion with depression was $94 \%$ (60\% in the second adjusted model), with anxiety $90 \%$ (42\%), and with suicidal thinking $80 \%$ (17\%).

We repeated the analysis to distinguish between coercive control by an intimate partner or another marital family member. In this case, the variable describing coercive control was based on 16 questions rather than 24 . The odds of a positive screen for moderate or severe depression or anxiety were higher when coercive control was exercised by an intimate partner (aOR2 2.8; $95 \%$ CI 2.0, 4.0 for depression, $2.5 ; 1.5,4.0$ for anxiety) than by a marital family member (1.8; 1.3, 2.5 for depression, $1.7 ; 1.1,2.7$ for anxiety). They were greatest when respondents reported that coercive control came from an intimate partner and marital family: aOR2 2.8 (95\% CI 2.0, $3.9)$ for depression and $2.8(1.7,4.6)$ for anxiety. 


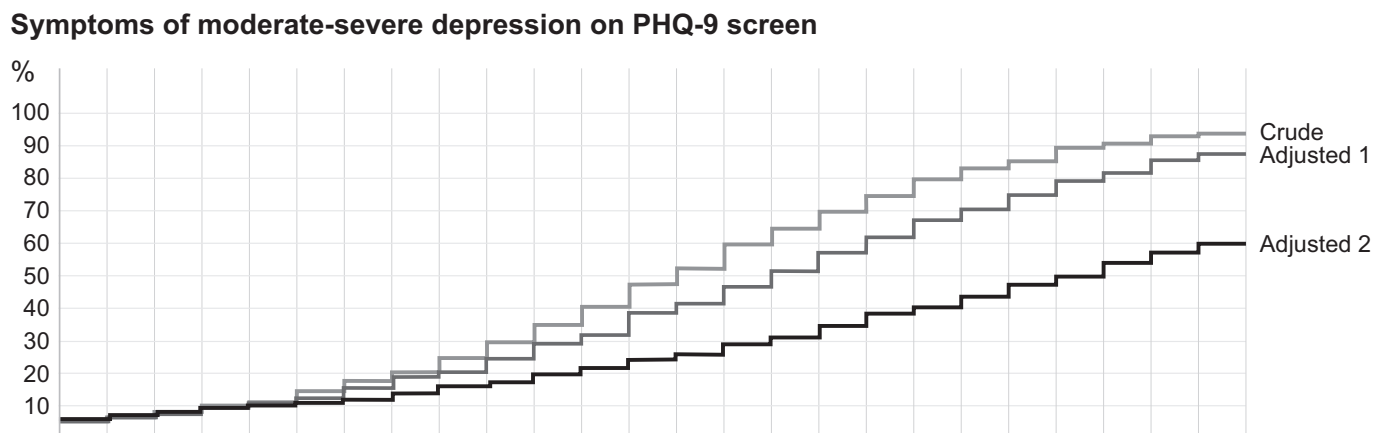

$\begin{array}{lllllllllllllllllllllllll}0 & 1 & 2 & 3 & 4 & 5 & 6 & 7 & 8 & 9 & 10 & 11 & 12 & 13 & 14 & 15 & 16 & 17 & 18 & 19 & 20 & 21 & 22 & 23 & 24\end{array}$

Number of indicators of coercive control reported by participant

Symptoms of moderate-severe anxiety on GAD-7 screen

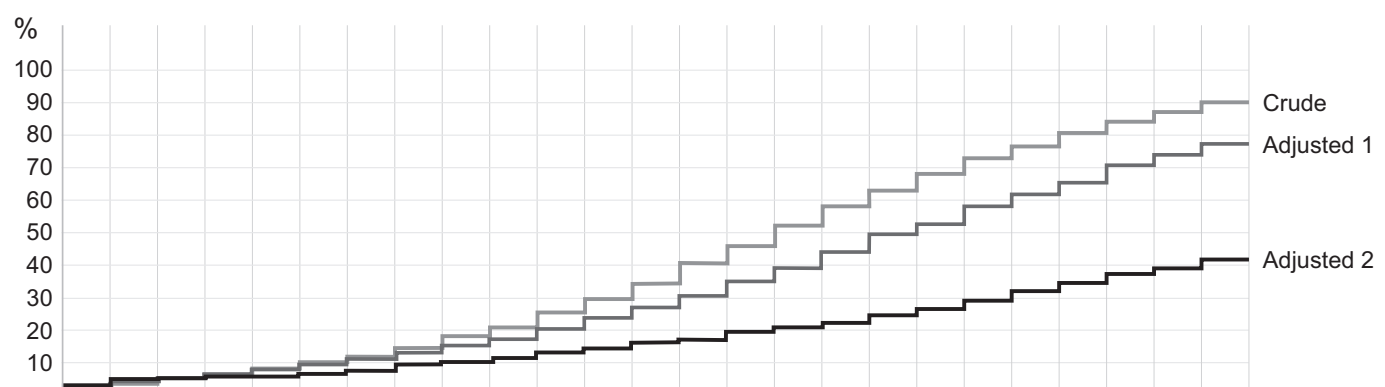

$\begin{array}{lllllllllllllllllllllllll}0 & 1 & 2 & 3 & 4 & 5 & 6 & 7 & 8 & 9 & 10 & 11 & 12 & 13 & 14 & 15 & 16 & 17 & 18 & 19 & 20 & 21 & 22 & 23 & 24\end{array}$

Number of indicators of coercive control reported by participant

\section{Suicidal thinking}

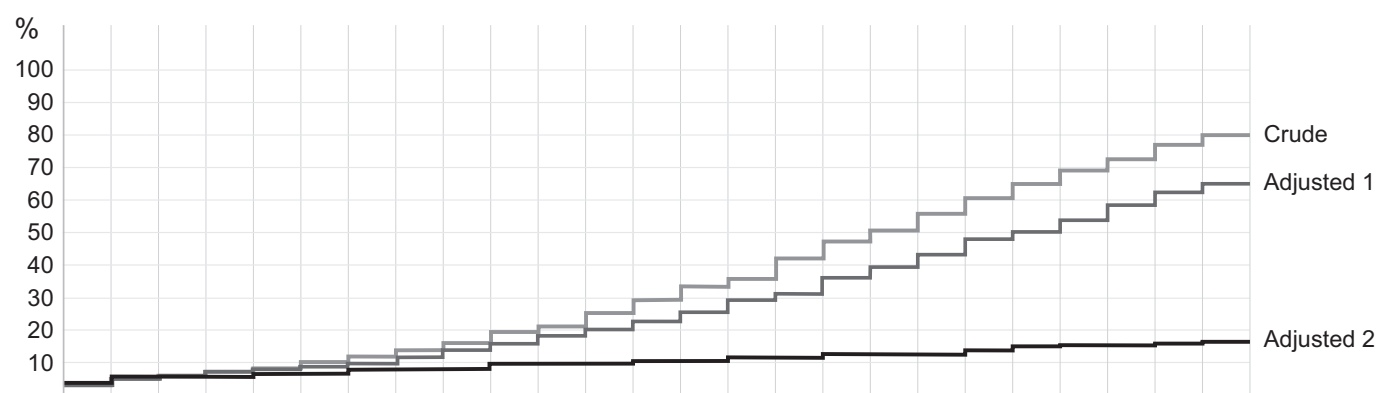

$\begin{array}{lllllllllllllllllllllllll}0 & 1 & 2 & 3 & 4 & 5 & 6 & 7 & 8 & 9 & 10 & 11 & 12 & 13 & 14 & 15 & 16 & 17 & 18 & 19 & 20 & 21 & 22 & 23 & 24\end{array}$

Number of indicators of coercive control reported by participant

Figure 1. The proportion of women with moderate-severe depression on the PHQ-9 screen, moderate-severe anxiety on the GAD-7 screen, or suicidal thoughts or action, conditional on the experience of 0-24 forms of coercive control behaviour. 


\section{Discussion}

In a survey of over 4000 ever-married women aged 18-49 years in informal settlements in Mumbai, $71 \%$ reported at least one form of domestic coercive control. Coercive control was independently associated with double the odds of positive screens for moderate or severe depression, moderate or severe anxiety, and suicidal thinking. The odds of these increased with each additional form of coercive control a woman reported. Coercive control by an intimate partner appeared to have a more substantial influence on depression and anxiety than control by a marital family member. The focus group discussions with counsellors, lawyers and community actors corroborated the results of the study. The themes of non-recognition of coercive control behaviours strains on mental health, and more propensity to abuse and violence emerged from the focus group discussions. The insidious and subtle nature of coercive control tactics made it harder for domestic violence survivors to recognize and deal with it.

Coercive control is a critical element of domestic violence. It makes possible, legitimises, and reinforces other forms of violence by limiting women's access to resources, harming their selfesteem, self-efficacy, and mental health, and isolating them or reducing their social support (Sowislo \& Orth, 2013; Stark, 2007; Thompson et al., 2002). Our results align with the feminist view that spouses commonly use controlling behaviour to subjugate women (Ali \& Naylor, 2013; McPhail et al., 2007; Yllo, 2005). At 71\%, the prevalence of coercive control in our study was high. Two possible reasons for this - apart from its ubiquity - are that we captured control by intimate partners and marital family members and that asking questions about specific behaviours might be more likely to elicit positive responses than asking more generally about something that might not be thought of as abusive in a situation in which it accords with gender norms.

The association of coercive control with emotional, physical, and sexual violence in the past year was consistent with other studies (Aizpurua et al., 2021; Biswas et al., 2017; Dalal \& Lindqvist, 2010; Donta et al., 2015; Gage \& Hutchinson, 2006; Krantz \& Vung, 2009; Mandal \& Hindin, 2013; Mukherjee \& Joshi, 2019; Ram et al., 2019). Links between intimate partner violence and various socially controlling behaviours have been found cross-culturally (Russo \& Pirlott, 2006), and the risk of violence has been described as increasing with the number of controlling behaviours across diverse cultures (Kishor \& Johnson, 2004). Representative studies from Thailand, Nepal, Nigeria, and Turkey have found that marital control by husbands increased the likelihood of spousal violence (Antai, 2011; Chuemchit et al., 2018; Gautam \& Jeong, 2019; Yüksel-Kaptanoğlu et al., 2012). Studies in England and the USA found that emotional abuse and marital controlling behaviour were risk factors for physical and sexual intimate partner violence (Felson \& Messner, 2000; Hamby \& Sugarman, 1999). A second important finding was that coercive control was associated independently with mental health concerns (Abbott et al., 1995; Bergman \& Brismar, 1991; Frye et al., 2006; Leone, 2010; Wolford-Clevenger \& Smith, 2017; Wolford-Clevenger et al., 2016). It effectively doubled the odds of depression, anxiety, and suicidal thinking, the odds increasing with each additional item in a way generally consistent with previous studies in India (Ahuja et al., 2000; Indu et al., 2017; Nur, 2012; Stephenson et al., 2013; Vachher \& Sharma, 2010; Varma et al., 2007). Coercive control targets the survivor's autonomy, equality, liberty, social support, and dignity in ways that compromise her capacity for independent, self-interested decision-making vital to escape or resist (Stark, 2012). Constraining a woman's social networks and using psychologically abusive tactics harms her physical and psychological well-being and wears down her will and ability to resist. Separation from family and friends may create a sense of futility and despair. When resistance is lower, compliance with 
coercive demands may be more likely since there are fewer resources to combat the pressure to comply (Dutton et al., 2006; Stark, 2012). This constrained daily life experience increases the risk of severe injury (Stark, 2007) and contributes to harms to mental health that may be more than those caused by physical violence (Daruwalla et al., 2020; Wolford-Clevenger et al., 2017).

Our focus on coercive control does not imply that the other forms of violence are unimportant: it is part of a matrix of abuse (Myhill \& Hohl, 2016). Offenders can subjugate and entrap victims without the use of physical violence, recognising that their controlling tactics will not be taken seriously (Hester \& Westmarland, 2006). Controlling tactics, however, predict a range of harms, including sexual, physical and fatal violence, better than prior assault (Beck \& Raghavan, 2010; Glass et al., 2004). Adopting the coercive control model would broaden our understanding of partner abuse to resemble most survivors' experience and improve intervention. Advocacy might encourage a legal view of coercive control as a "liberty crime" (Johnson, 2006; Stark, 2007).

\section{Limitations}

In the absence of a valid measure of coercive control,we asked 24 questions designed to describe a spectrum of coercive controlling behaviours.For this reason our findings are not directly comparable with those of other studies, althoughsimilar forms of restriction, isolation, and control are recognised as abusive by women in many countries (Butterworth \& Westmarland, 2015; Hester et al., 2017), and we used many similar questions (Beck \& Raghavan, 2010; Dalal \& Lindqvist, 2010; Dutton et al., 2006; Mukherjee \& Joshi, 2019; Stark \& Hester, 2019; Williamson, 2010; Wolford-Clevenger et al., 2017). Our estimates of prevalence may have been increased by the emphasis on sampling younger women and achieving representation of women with disability and the cross-sectional study design means that we are unable to make causal inferences. Of particular note is the (probably) bidirectional relationship between forms of domestic violence and mental health. We cannot say whether domestic violence was the cause or effect of disturbed mental health. Nor did our models include information on the mental health of intimate partners or other family members. Informal settlements may themselves influence the risk of domestic violence and poor mental health in ways for which we were unable to adjust.

\section{Diversity}

The diversity of our study was limited as it involved women aged 18-49 years living in informal settlements. For this reason, the sample represented poorer women and did not involve children, men, or women over the age of 50Transgender women were included and we encouraged inclusion of people with disability.

\section{Conclusion}

Our study considered coercive control as part of the spectrum of domestic violence. It contributes to the disproportionately small evidence base from low- or middle-income settings and considers violence by intimate partners and other family members. Coercive control appears to be a major component of domestic violence and an independent risk factor for depression, anxiety, and suicidal thinking. Understandably, the current focus is on physical and sexual violence, but this needs to expand to consider the controlling behaviours that are often apparent before the physical injury.

For policy and practice, there is enough evidence that the harms of coercive control are as devastating as physical and sexual violence; what is lacking is recognition in legal and healthcare systems. Coercive control needs to be recognised by both policymakers and practitioners as a 
central feature of domestic violence. It does not feature in India's Protection of Women from Domestic Violence Act, 2005 (Government of India, 2005). Although the Act was designed to protect women from future domestic violence, it only acknowledges the importance of economic abuse and dowry violence and does not recognize fully that emotional abuse and coercive control limit women's access to social support, services, and resources. Practitioners need to be aware that women experiencing coercive control require social, legal, and medical attention. Early intervention will protect some women from progression to, for example, physical domestic violence, as well as from harms to mental health and isolation.

\section{Acknowledgments}

We are grateful to the women and community guardians who agreed to contribute to the study. We thank the investigators and supervisors Miheeka Vast and Manju Singh, Unnati Machchhar and Shilpa Adelkar for management of the intervention, Bhaskar Kakad for supervision, Gauri Savkur for training support, Archana Bagra and Vibhavari Bali for financial and human resources management, and Vanessa D'Souza and Shanti Pantvaidya for leadership at SNEHA.

\section{Author Contributions}

$\mathrm{ND}$ and $\mathrm{DO}$ acquired funding, and ND was responsible for managing the project. SK, ND, and DO conceived and designed the work. SK designed the data collection materials and managed the acquisition of data under ND and DO guidance. SK analyzed with help from DO. SK interpreted the data and wrote the first draft, and ND, MS, LG, and DO contributed to subsequent drafts. All authors revised the draft critically for intellectual content and approved the final version. The authors agree to be accountable for all aspects of the work in ensuring that questions related to the accuracy or integrity of any part of it are appropriately investigated and resolved.

\section{Data Sharing}

Data are available in the Open Science Framework: Suman Kanougiya (2021, February 26). Coercive control dataset. Retrieved from https://osf.io/4y6vd/

\section{Declaration of Conflicting Interests}

The author(s) declared no potential conflicts of interest with respect to the research, authorship, and/or publication of this article.

\section{Funding}

The author(s) disclosed receipt of the following financial support for the research, authorship, and/or publication of this article: This research was funded by the Wellcome Trust (206417). For the purpose of Open Access, the authors have applied a CC BY public copyright license to any author accepted manuscript version arising from this submission. The funder had no role in study design, data collection and analysis, decision to publish, or preparation of the manuscript. 


\section{References}

Abbott, J., Johnson, R., Koziol-McLain, J., \& Lowenstein, S. R. (1995). Domestic violence against women. Incidence and prevalence in an emergency department population. JAMA: Journal of the American Medical Association, 273(22), 1763-1767. https://doi.org/10.1001/jama.273.22.1763

Ahuja, R. C., Bangdiwala, S., Bhambal, S. S., Jain, D., Jeyaseelan, L., Kumar, S., Lakshman, M., Mitra, M. K., Nair, M. K. C., \& Pillai, R. (2000). Domestic violence in India- a summary report of a multi-site household survey.

Aizpurua, E., Copp, J., Ricarte, J. J., \& Vázquez, D. (2021). Controlling Behaviors and Intimate Partner Violence Among Women in Spain: An Examination of Individual, Partner, and Relationship Risk Factors for Physical and Psychological Abuse. Journal of Interpersonal Violence 36(1-2), 231254. https://doi.org/10.1177/0886260517723744

Ali, P. A., \& Naylor, P. B. (2013, 2013/11/01/). Intimate partner violence: A narrative review of the feminist, social and ecological explanations for its causation. Aggression and Violent Behavior, 18(6), 611-619. https://doi.org/https://doi.org/10.1016/j.avb.2013.07.009

Anderson, K. L. (2008). Is partner violence worse in the context of control? Journal of Marriage and Family, 70(5), 1157-1168.

Antai, D. (2011). Controlling behavior, power relations within intimate relationships and intimate partner physical and sexual violence against women in Nigeria. Biomed Central Public Health, 11, 511. https://doi.org/10.1186/1471-2458-11-511

Beck, C., \& Raghavan, C. (2010). Intimate partner abuse screening in custody mediation: The importance of assessing coercive control. Family Court Review, 48(3), 555-565. https://doi.org/https://doi.org/10.1111/j.1744-1617.2010.01329.x

Bergman, B., \& Brismar, B. (1991). Suicide attempts by battered wives. Acta Psychiatrica Scandinavica, 83(5), 380-384. https://doi.org/10.1111/j.1600-0447.1991.tb05560.x

Bishop, C., \& Bettinson, V. (2017). Evidencing domestic violence, including behaviour that falls under the new offence of 'controlling or coercive behaviour'. International Journal of Evidence and Proof, 22(1), 3-29. https://doi.org/10.1177/1365712717725535

Biswas, R. K., Rahman, N., Kabir, E., \& Raihan, F. (2017). Women's opinion on the justification of physical spousal violence: A quantitative approach to model the most vulnerable households in Bangladesh. PLOS ONE, 12(11), e0187884. https://doi.org/10.1371/journal.pone.0187884

Butterworth, K., \& Westmarland, N. (2015). Victims' Views on Policing Partner Violence. European Law Enforcement Research Bulletin(13), 60-63. Retrieved from http://91.82.159.234/index.php/bulletin/article/view/126

Campbell, J. C., Webster, D., Koziol-McLain, J., Block, C., Campbell, D., Curry, M. A., Gary, F., Glass, N., McFarlane, J., Sachs, C., Sharps, P., Ulrich, Y., Wilt, S. A., Manganello, J., Xu, X., Schollenberger, J., Frye, V., \& Laughon, K. (2003). Risk factors for femicide in abusive relationships: results from a multisite case control study. American Journal of Public Health, 93(7), 1089-1097. https://doi.org/10.2105/ajph.93.7.1089

Chandramouli, C. (2011). Housing stock, amenities and assets in slums-census 2011. Office of the Registrar General and Census Commissioner.

Chuemchit, M., Chernkwanma, S., Rugkua, R., Daengthern, L., Abdullakasim, P., \& Wieringa, S. E. (2018). Prevalence of Intimate Partner Violence in Thailand. Journal of Family Violence, 33(5), 315-323. https://doi.org/10.1007/s10896-018-9960-9 
Crossman, K. A., Hardesty, J. L., \& Raffaelli, M. (2015). "He Could Scare Me Without Laying a Hand on Me": Mothers' Experiences of Nonviolent Coercive Control During Marriage and After Separation. Violence Against Women, 22(4), 454-473. https://doi.org/10.1177/1077801215604744

Dalal, K., \& Lindqvist, K. (2010). A National Study of the Prevalence and Correlates of Domestic Violence Among Women in India. Asia Pacific Journal of Public Health, 24(2), 265-277. https://doi.org/10.1177/1010539510384499

Daruwalla, N., Kanougiya, S., Gupta, A., Gram, L., \& Osrin, D. (2020). Prevalence of domestic violence against women in informal settlements in Mumbai, India: a cross-sectional survey. BMJ Open, 10(12), e042444. https://doi.org/10.1136/bmjopen-2020-042444

Daruwalla, N., Machchhar, U., Pantvaidya, S., D’Souza, V., Gram, L., Copas, A., \& Osrin, D. (2019). Community interventions to prevent violence against women and girls in informal settlements in Mumbai: the SNEHA-TARA pragmatic cluster randomised controlled trial. Trials, 20(1), 743. https://doi.org/10.1186/s13063-019-3817-2

Dekeseredy, W. S., \& Schwartz, M. D. (2011). Theoretical and definitional issues in violence against women. In C. M. Renzetti, J. L. Edleson, \& R. K. Bergen (Eds.), Sourcebook on violence against women (pp. 3-22). SAGE. https://doi.org/10.4135/9781452224916 n1

Dobash, R. E., \& Dobash, R. P. (2015). When men murder women [doi:10.1093/acprof:oso/9780199914784.001.0001]. Oxford University Press. https://doi.org/10.1093/acprof:oso/9780199914784.001.0001

Donta, B., Nair, S., Begum, S., \& Prakasam, C. P. (2015). Association of Domestic Violence From Husband and Women Empowerment in Slum Community, Mumbai. Journal of interpersonal violence, 31(12), 2227-2239. https://doi.org/10.1177/0886260515573574

Dutton, M. A., Goodman, L. A., \& Bennett, L. (1999, Spring). Court-involved battered women's responses to violence: the role of psychological, physical, and sexual abuse. Violence and Victims, 14(1), 89-104.

Dutton, M. A., Goodman, L. A., \& Schmidt, R. J. (2006). Development and Validation of a Coercive Control Measure for Intimate Partner Violence: Final Technical Report https://www.ojp.gov/pdffiles1/nij/grants/214438.pdf

Dutton, M. A., Haywood, Y., \& El-Bayoumi, G. (1997). Impact of violence on women's health. In S. J. Gallant, G. P. Keita, \& R. Royak-Shaler (Eds.), Health care for women: Psychological, Social, and Behavioral Influences (pp. 41-56). American Psychological Association. https://doi.org/10.1037/10235-003

Ellsberg, M., \& Heise, L. (2005). Researching Violence Against Women: A Practical Guide for Researchers and Activists.

Felson, R. B., \& Messner, S. F. (2000). The Control Motive in Intimate Partner Violence. Social Psychology Quarterly, 63(1), 86-94. https://doi.org/10.2307/2695883

Filmer, D., \& Pritchett, L. H. (2001). Estimating Wealth Effects Without Expenditure Data-Or Tears: An Application To Educational Enrollments In States Of India. Demography, 38(1), 115-132. https://doi.org/10.1353/dem.2001.0003

Follingstad, D. R., Brennan, A. F., Hause, E. S., Polek, D. S., \& Rutledge, L. L. (1991). Factors moderating physical and psychological symptoms of battered women. Journal of Family Violence, 6(1), 81-95. https://doi.org/10.1007/BF00978527 
Follingstad, D. R., Rutledge, L. L., Berg, B. J., Hause, E. S., \& Polek, D. S. (1990). The role of emotional abuse in physically abusive relationships. Journal of Family Violence, 5(2), 107-120. https://doi.org/10.1007/BF00978514

Frye, V., Manganello, J., Campbell, J. C., Walton-Moss, B., \& Wilt, S. (2006). The Distribution of and Factors Associated With Intimate Terrorism and Situational Couple Violence Among a Population-Based Sample of Urban Women in the United States. Journal of interpersonal violence, 21(10), 1286-1313. https://doi.org/10.1177/0886260506291658

Gage, A. J., \& Hutchinson, P. L. (2006). Power, Control, and Intimate Partner Sexual Violence in Haiti. Archives of Sexual Behavior, 35(1), 11-24. https://doi.org/10.1007/s10508-006-8991-0

García-Moreno, C., Jansen, H. A., Ellsberg, M., Heise, L., \& Watts, C. (2005). WHO multi-country study on women's health and domestic violence against women.

Gautam, S., \& Jeong, H.-S. (2019). Intimate Partner Violence in Relation to Husband Characteristics and Women Empowerment: Evidence from Nepal. International Journal of Environmental Research and Public Health, 16(5), 709. https://www.mdpi.com/1660-4601/16/5/709

Glass, N., Manganello, J., \& Campbell, J. C. (2004). Risk for intimate partner femicide in violent relationships. Domestic Violence Report, 9(2), 1.

Government of India. (2005). The Protection of Women from Domestic Violence Act, 2005. Legislative Department.

Graham-Kevan, N., \& Archer, J. (2003). Intimate Terrorism and Common Couple Violence: A Test of Johnson's Predictions in Four British Samples. Journal of interpersonal violence, 18(11), 12471270. https://doi.org/10.1177/0886260503256656

Hamby, S. L., \& Sugarman, D. B. (1999). Acts of Psychological Aggression against a Partner and Their Relation to Physical Assault and Gender. Journal of Marriage and Family, 61(4), 959-970. https://doi.org/10.2307/354016

Hardesty, J. L., Crossman, K. A., Haselschwerdt, M. L., Raffaelli, M., Ogolsky, B. G., \& Johnson, M. P. (2015). Toward a Standard Approach to Operationalizing Coercive Control and Classifying Violence Types. Journal of Marriage and Family, 77(4), 833-843. https://doi.org/https://doi.org/10.1111/jomf.12201

Hester, M., Jones, C., Williamson, E., Fahmy, E., \& Feder, G. (2017). Is it coercive controlling violence? A cross-sectional domestic violence and abuse survey of men attending general practice in England. Psychology of Violence, 7(3), 417-427. https://doi.org/10.1037/vio0000107

Hester, M., \& Westmarland, N. (2006). Domestic violence perpetrators. Criminal Justice Matters, 66(1), 34-35. https://doi.org/10.1080/09627250608553400

Howard, L., S., O., Galley, H., Trevillion, K., \& Feder, G. (2013). Domestic Violence and Perinatal Mental Disorders: A Systematic Review and Meta-Analysis. PLOS Medicine, 10(5), e1001452. https://doi.org/10.1371/journal.pmed.1001452

Indu, P. V., Remadevi, S., Vidhukumar, K., Shah Navas, P. M., Anilkumar, T. V., \& Subha, N. (2017). Domestic Violence as a Risk Factor for Attempted Suicide in Married Women. Journal of interpersonal violence, 35(23-24), 5753-5771. https://doi.org/10.1177/0886260517721896

International Institute for Population Sciences, \& ICF. (2017). National Family Health Survey (NFHS-4), 2015-16. International Institute for Population Sciences.

International Institute for Population Sciences (IIPS), \& ICF. (2017). National Family Health Survey (NFHS-4), 2015-16. 
Jewkes, R., Dartnall, E., \& Sikweyiya, Y. (2012). Ethical and safety recommendations for research on perpetration of sexual violence. Sexual Violence Research Initiative, Medical Research Council.

Johnson, M. P. (2006). Conflict and Control: Gender Symmetry and Asymmetry in Domestic Violence. Violence Against Women, 12(11), 1003-1018. https://doi.org/10.1177/1077801206293328

Kalokhe, A. S., Iyer, S. R., Kolhe, A. R., Dhayarkar, S., Paranjape, A., Del Rio, C., Stephenson, R., \& Sahay, S. (2018). Correlates of domestic violence experience among recently-married women residing in slums in Pune, India. PLOS ONE, 13(4), e0195152. https://doi.org/10.1371/journal.pone.0195152

Kalokhe, A. S., Stephenson, R., Kelley, M. E., Dunkle, K. L., Paranjape, A., Solas, V., Karve, L., del Rio, C., \& Sahay, S. (2016). The Development and Validation of the Indian Family Violence and Control Scale. PLOS ONE, 11(1), e0148120. https://doi.org/10.1371/journal.pone.0148120

Kelly, J. B., \& Johnson, M. P. (2008). Differentiation among types of intimate partner violence: Research update and implications for interventions. Family Court Review, 46(3), 476-499. https://doi.org/https://doi.org/10.1111/j.1744-1617.2008.00215.x

Kirkwood, C., \& Gilbert, L. (1995). Leaving Abusive Partners: From the Scars of Survival to the Wisdom for Change. Psyccritiques, 40(1), 71-72. https://doi.org/DOI: 10.1037/003365

Kishor, S., \& Johnson, K. (2004). Profiling Domestic Violence- A Multi-Country Study. ORC Macro.

Krantz, G., \& Vung, N. D. (2009). The role of controlling behaviour in intimate partner violence and its health effects: a population based study from rural Vietnam. Biomed Central Public Health, 9(1), 143. https://doi.org/10.1186/1471-2458-9-143

Kroenke, K., Spitzer, R. L., \& Williams, J. B. W. (2001). The PHQ-9: validity of a brief depression severity measure. Journal of General Internal Medicine, 16(9), 606-613. https://doi.org/https://doi.org/10.1046/j.1525-1497.2001.016009606.x

Leone, J. M. (2010). Suicidal Behavior Among Low-Income, African American Female Victims of Intimate Terrorism and Situational Couple Violence. Journal of interpersonal violence, 26(13), 2568-2591. https://doi.org/10.1177/0886260510388280

Lischick, C. W. (1999). Coping and related characteristics delineating battered women's experiences in self-defined, difficult/hurtful dating relationships: A multicultural study(0599298367).

Löwe, B., Decker, O., Müller, S., Brähler, E., Schellberg, D., Herzog, W., \& Herzberg, P. Y. (2008). Validation and Standardization of the Generalized Anxiety Disorder Screener (GAD-7) in the General Population. Medical Care, 46(3), 266-274. http://www.jstor.org/stable/40221654

Löwe, B., Spitzer, R. L., Gräfe, K., Kroenke, K., Quenter, A., Zipfel, S., Buchholz, C., Witte, S., \& Herzog, W. (2004). Comparative validity of three screening questionnaires for DSM-IV depressive disorders and physicians' diagnoses. Journal of Affective Disorders, 78(2), 131-140. https://doi.org/https://doi.org/10.1016/S0165-0327(02)00237-9

Mandal, M., \& Hindin, M. J. (2013). Men's Controlling Behaviors and Women's Experiences of Physical Violence in Malawi. Maternal and Child Health Journal, 17(7), 1332-1338. https://doi.org/10.1007/s10995-012-1137-1

McKinnon, B., Gariépy, G., Sentenac, M., \& Elgar, F. J. (2016). Adolescent suicidal behaviours in 32 low- and middle-income countries. Bulletin of the World Health Organization, 94(5), 340-350F. https://doi.org/10.2471/BLT.15.163295

McPhail, B. A., Busch, N. B., Kulkarni, S., \& Rice, G. (2007). An Integrative Feminist Model: The Evolving Feminist Perspective on Intimate Partner Violence. Violence Against Women, 13(8), 817-841. https://doi.org/10.1177/1077801207302039 
Mukherjee, R., \& Joshi, R. K. (2019). Controlling Behavior and Intimate Partner Violence: A CrossSectional Study in an Urban Area of Delhi, India. Journal of interpersonal violence, September 2019, 886260519876720. https://doi.org/10.1177/0886260519876720

Myhill, A. (2015). Measuring Coercive Control: What Can We Learn From National Population Surveys? Violence Against Women, 21(3), 355-375. https://doi.org/10.1177/1077801214568032

Myhill, A., \& Hohl, K. (2016). The "Golden Thread": Coercive Control and Risk Assessment for Domestic Violence. Journal of interpersonal violence, 34(21-22), 4477-4497. https://doi.org/10.1177/0886260516675464

Nur, N. (2012). The Effect of Intimate Partner Violence on Mental Health Status Among Women of Reproductive Ages: A Population-Based Study in a Middle Anatolian City. Journal of interpersonal violence, 27(16), 3236-3251. https://doi.org/10.1177/0886260512441255

O'Leary, K. D., Malone, J., \& Tyree, A. (1994). Physical aggression in early marriage: Prerelationship and relationship effects. Journal of Consulting Clinical Psychology, 62(3), 594-602. https://doi.org/10.1037/0022-006X.62.3.594

Pandey, G. K., Dutt, D., \& Banerjee, B. (2009, Jul). Partner and relationship factors in domestic violence: perspectives of women from a slum in Calcutta, India. J Interpers Violence, 24(7), 1175-1191. https://doi.org/10.1177/0886260508322186

Ram, A., Victor, C. P., Christy, H., Hembrom, S., Cherian, A. G., \& Mohan, V. R. (2019). Domestic Violence and its Determinants among 15-49-Year-Old Women in a Rural Block in South India. Indian Journal of Community Medicine, 44(4), 362-367. https://doi.org/10.4103/ijcm.IJCM_84_19

Richardson, R., Nandi, A., Jaswal, S., \& Harper, S. (2020). The effect of intimate partner violence on women's mental distress: a prospective cohort study of 3010 rural Indian women. Social Psychiatry and Psychiatric Epidemiology, 55(1), 71-79. https://doi.org/10.1007/s00127-019$\underline{01735-5}$

Russo, N. F., \& Pirlott, A. (2006). Gender-based violence: concepts, methods, and findings. Annals of the New York Academy of Sciences, 1087, 178-205. https://doi.org/10.1196/annals.1385.024

Sapkota, D., Bhattarai, S., Baral, D., \& Pokharel, P. K. (2016). Domestic violence and its associated factors among married women of a village development committee of rural Nepal. Biomed Central Research Notes, 9(1), 178. https://doi.org/10.1186/s13104-016-1986-6

Sowislo, J. F., \& Orth, U. (2013). Does low self-esteem predict depression and anxiety? A meta-analysis of longitudinal studies. Psychological bulletin, 139(1), 213-240. https://doi.org/10.1037/a0028931

Spitzer, R. L., Kroenke, K., Williams, J. B. W., \& Löwe, B. (2006). A Brief Measure for Assessing Generalized Anxiety Disorder: The GAD-7. Archives of Internal Medicine, 166(10), 1092-1097. https://doi.org/10.1001/archinte.166.10.1092

Stark, E. (2007). Coercive control: How men entrap women in personal life. Oxford University Press.

Stark, E. (2012). Re-presenting battered women: Coercive control and the defense of liberty. Violence Against Women: Complex Realities and New Issues in a Changing World, Québec.

Stark, E., \& Hester, M. (2019). Coercive Control: Update and Review. Violence Against Women, 25(1), 81-104. https://doi.org/10.1177/1077801218816191

Stephenson, R., Winter, A., \& Hindin, M. (2013). Frequency of Intimate Partner Violence and Rural Women's Mental Health in Four Indian States. Violence Against Women, 19(9), 1133-1150. https://doi.org/10.1177/1077801213501898 
Straus, M. A., Hamby, S. L., Boney-McCoy, S. U. E., \& Sugarman, D. B. (1996). The Revised Conflict Tactics Scales (CTS2): Development and Preliminary Psychometric Data. Journal of Family Issues, 17(3), 283-316. https://doi.org/10.1177/019251396017003001

Suarez, K. (1994). Teenage Dating Violence: The Need for Expanded Awareness and Legislation. California Law Review, 82(2), 423-471. https://doi.org/10.2307/3480981

Tanha, M., Beck, C. J. A., Figueredo, A. J., \& Raghavan, C. (2009). Sex Differences in Intimate Partner Violence and the Use of Coercive Control as a Motivational Factor for Intimate Partner Violence. Journal of interpersonal violence, 25(10), 1836-1854. https://doi.org/10.1177/0886260509354501

Thompson, M. P., Kaslow, N. J., Short, L. M., \& Wyckoff, S. (2002). The mediating roles of perceived social support and resources in the self-efficacy-suicide attempts relation among African American abused women. Journal of Consulting Clinical Psychology, 70(4), 942-949. https://doi.org/10.1037//0022-006x.70.4.942

Tolman, R. M. (1992). Psychological abuse of women. In R. T. Ammerman \& M. Hersen (Eds.), Wiley series on personality processes. Assessment of family violence: A clinical and legal sourcebook. (pp. 291-310). John Wiley \& Sons.

UN Assembly. (2000). United Nations Millennium Declaration (Vol. 156). United Nations Department of Public Information.

United Nations Human Settlements Programme (UN-Habitat). (2003). The challenge of slums: global report on human settlements 2003. Earthscan Publications Ltd.

Vachher, A. S., \& Sharma, A. (2010). Domestic violence against women and their mental health status in a colony in Delhi. Indian Journal of Community Medicine, 35(3), 403-405. https://doi.org/10.4103/0970-0218.69266

Varma, D., Chandra, P. S., Thomas, T., \& Carey, M. P. (2007). Intimate partner violence and sexual coercion among pregnant women in India: Relationship with depression and post-traumatic stress disorder. Journal of Affective Disorders, 102(1), 227-235. https://doi.org/https://doi.org/10.1016/j.jad.2006.09.026

Vyas, S., \& Kumaranayake, L. (2006). Constructing socio-economic status indices: how to use principal components analysis. Health Policy and Planning, 21(6), 459-468. https://doi.org/10.1093/heapol/czl029

WHO. (2012). Risks to mental health: An overview of vulnerabilities and risk factors. Background paper by WHO Secretariat for the development of a comprehensive Mental Health Action Plan.

Williamson, E. (2010). Living in the World of the Domestic Violence Perpetrator: Negotiating the Unreality of Coercive Control. Violence Against Women, 16(12), 1412-1423. https://doi.org/10.1177/1077801210389162

Wolford-Clevenger, C., Grigorian, H., Brem, M., Florimbio, A., Elmquist, J., \& Stuart, G. L. (2017). Associations of Emotional Abuse Types With Suicide Ideation Among Dating Couples. Journal of Aggression, Maltreatment and Trauma, 26(9), 1042-1054. https://doi.org/10.1080/10926771.2017.1335821

Wolford-Clevenger, C., \& Smith, P. N. (2017). The conditional indirect effects of suicide attempt history and psychiatric symptoms on the association between intimate partner violence and suicide ideation. Personality and Individual Differences, 106, 46-51. https://doi.org/https://doi.org/10.1016/j.paid.2016.10.042 
Wolford-Clevenger, C., Vann, N. C., \& Smith, P. N. (2016). The Association of Partner Abuse Types and Suicidal Ideation Among Men and Women College Students. Violence and Victims, 31(3), 471485. https://doi.org/10.1891/0886-6708.Vv-d-14-00083

Yllo, K. A. (2005). Through a Feminist Lens : Gender, Diversity, and Violence: Extending the Feminist Framework. In D. R. Loseke, R. J. Gelles, \& M. M. Cavanaugh (Eds.), Current controversies on family violence (pp. 47-62). SAGE Publications Inc. https://ci.nii.ac.jp/naid/10024162109/en/

Yüksel-Kaptanoğlu, İ., Türkyılmaz, A. S., \& Heise, L. (2012). What Puts Women at Risk of Violence From Their Husbands? Findings From a Large, Nationally Representative Survey in Turkey. Journal of interpersonal violence, 27(14), 2743-2769. https://doi.org/10.1177/0886260512438283 